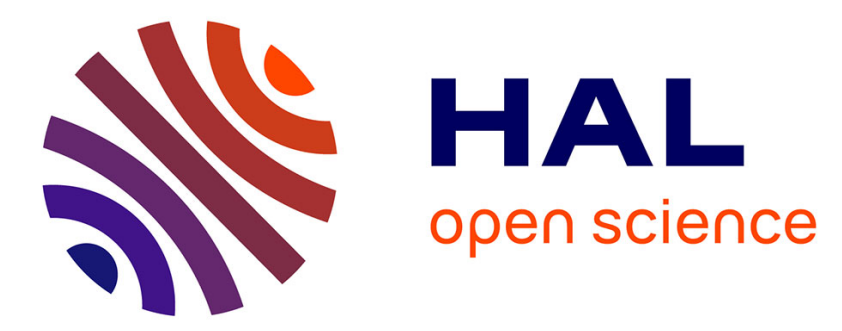

\title{
Outdoor thermal monitoring of large scale structures by infrared thermography integrated in an ICT based architecture
}

Jean Dumoulin, Antoine Crinière, Rodolphe Averty

\section{- To cite this version:}

Jean Dumoulin, Antoine Crinière, Rodolphe Averty. Outdoor thermal monitoring of large scale structures by infrared thermography integrated in an ICT based architecture. QCAV 2015 - International Conference on Quality Control by Artificial Vision, Jun 2015, Le Creusot, France. 10.1117/12.2185122 . hal-01230584

\section{HAL Id: hal-01230584 \\ https://hal.inria.fr/hal-01230584}

Submitted on 25 Nov 2015

HAL is a multi-disciplinary open access archive for the deposit and dissemination of scientific research documents, whether they are published or not. The documents may come from teaching and research institutions in France or abroad, or from public or private research centers.
L'archive ouverte pluridisciplinaire HAL, est destinée au dépôt et à la diffusion de documents scientifiques de niveau recherche, publiés ou non, émanant des établissements d'enseignement et de recherche français ou étrangers, des laboratoires publics ou privés. 


\title{
Outdoor thermal monitoring of large scale structures by infrared thermography integrated in an ICT based architecture
}

\author{
Jean Dumoulin ${ }^{\mathrm{a}, \mathrm{b}}$, Antoine Crinière ${ }^{\mathrm{b}}$ and Rodolphe Averty ${ }^{\mathrm{a}}$ \\ aLUNAM Université, IFSTTAR, COSYS, F-44340, Bouguenais, France \\ 'INRIA/IRISA, I4S Team, Campus de Beaulieu, 35042 Rennes cedex, France
}

\section{Extended Summary}

\section{Introduction}

With the constant increase of the road traffic coupled with the aging of transport infrastructure, studying and developing robust system which allows to monitor and assess those structures is of growing interest. Among the techniques used [1], thermal monitoring with infrared thermography appears to be a good compromise between a non-intrusive method and possible added value after post-processing of acquired data. Through the past decade studies have shown the ability to monitor concrete and asphalt structure by active IR thermography [2] [3]. On site measurement using passive thermography have also been studied, by applying qualitative methods [4] and quantitative one [5]. These methods have been used to perform punctual control of various duration (few hours to few days).

However, infrared thermography, when it is used in a quantitative mode (not in laboratory conditions) and not in a qualitative mode (vision applied to survey), needs to process thermal radiative corrections on the raw data acquired in real time, to take into account the influences of the natural environment's evolution with time. However the camera sensor has to be smart enough to apply calibration laws and radiometric corrections in real time in a varying atmosphere.

Those requirements mean the use of smart sensing techniques but also of embedded communication and processing units which allow to dynamically interact with raw and pre-processed data.

In such context, study and development of such smart infrared measurement system was initiated in the framework of the European project ISTIMES. The main objective of ISTIMES was to evaluate the potentialities offered by the integration of different electromagnetic techniques able to perform noninvasive diagnostics for the surveillance and monitoring of transport infrastructures [6]. Within this project, an information system, has been designed to perform very long term thermal monitoring of structures exposed to environmental condition, as the solar heat flux, natural convection or seasonal perturbation.

This system called "IrLaW" is based on a multi sensing approach. It connects and synchronizes information acquired by a weather station, a GPS and an infrared camera. To fulfill ICT objectives (OGC compliant), a specific hardware architecture was also designed and studied to allow the whole system integration in a TCP/IP network [7], also called the "Sensorbox" in this paper.

After introducing the ICT based infrared measurement system studied and developed for long term thermal monitoring of large scale structures, results obtained on various test sites will be presented. Finally a discussion will be proposed on results obtained on different test sites and for different duration from several days up to several months. Conclusion and perspectives will then be proposed.

\section{Smart infrared system designed and studied}

A Human Machine Interface (HMI) was designed and developed with multiple in-house infrared camera drivers including uncooled IRFPA microbolometers camera of FLIR series SC3xx and SC6xx. This $\mathrm{HMI}$ called "IrLaW" has various functionalities allowing its use either in real site for long term monitoring or in laboratory conditions (for instance for Non Destructive Testing experiments). 
Its standard functionalities allow image averaging, setting the number of frame by thermal image sequence saved, and changing the sampling frequency during an acquisition with no interruption. For field application, scenarios were implemented to generate automatically average image at a fixed frequency (while camera was running at higher frequency) and thermal image sequences were saved at fixed time period to avoid loss of data in case of malfunction.

As such system was designed for long term thermal monitoring of transport infrastructures, we also investigated a solution for its dissemination at a network level.

To reach that aim, we carried out a complementary design based on Information and Communications Technology (ICT) domain. In particular we addressed the Spatial Data Infrastructure concept to satisfy a "relevant base collection of technologies, policies and institutional arrangements that facilitate the availability of and access to spatial data". So we change from "traditional" data-centric approach, as illustrated before with our initial measurement system designed, to "infrastructure" or "system of systems" approach. For that we also addressed an advanced service-based approach and focused on multidisciplinary interoperability.

So, complementary developments were made to allow "IrLaW" to become an OGC (Open Geosciences Consortium - www.opengeospatial.org ) compliant infrared thermography measurement system.

At first we added a new capability to the system. It consists in managing various measurement channels that allow inline data processing and/or communication process without affecting initial measurement performed. Figure 1 shows a schematic view of the multichannel capability studied and implemented in the infrared measurement platform.

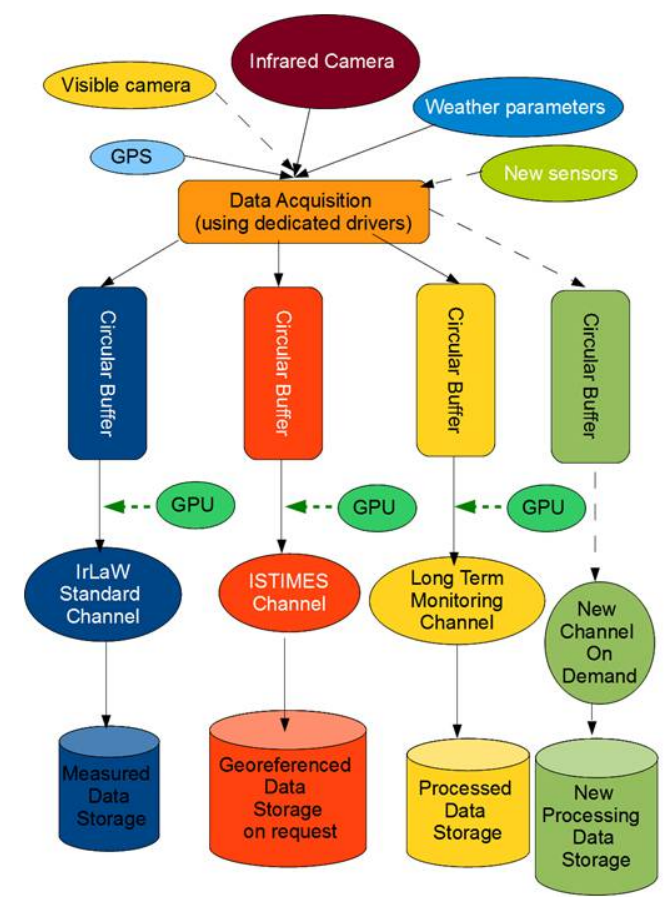

Fig. 1 Multi-channel infrared measurement platform architecture.

Thanks to that new capability, an OGC sensor web services has been added to the measurement system. In particular the following services have been implemented:

1. SOS (Sensor Observation Service) that provides access to observation from sensor.

2. SPS (Sensor Planning Service) that is mounted to provide a standard interface to collection assets (i.e., sensors, and other information gathering assets) and to the support systems that surround them.

3. A dedicated FTP server to locate the performed acquisition. 
As for other sensor in OGC environment (for instance thermal probe, humidity probe, wind speed probe), the infrared sensor is fully managed by our small system. Our platform controls the data acquisition, data processing and sensor interfacing.

So at the end the infrared measurement system designed and studied is interoperable locally and through web.

Next paragraph presents results obtained on various large scale structures.

\section{Results obtained on large structures}

\subsection{Thermal monitoring of bridges over several days}

During these field tests on real bridges open to traffic, corrected data were acquired at a frame rate of $0.1 \mathrm{~Hz}$ by averaging 50 thermal images with an initial fixed camera frame rate of $5 \mathrm{~Hz}$. Each hour, a thermal image sequence was stored on the internal hard drive of our system and data were retrieved (on demand) using a wireless connection on a notebook computer

First illustration of results, presents the measurement system and an uninterruptible power supply placed on a sign deck above the Sihlhochstrasse bridge in Zurich, Switzerland (see figure 2).
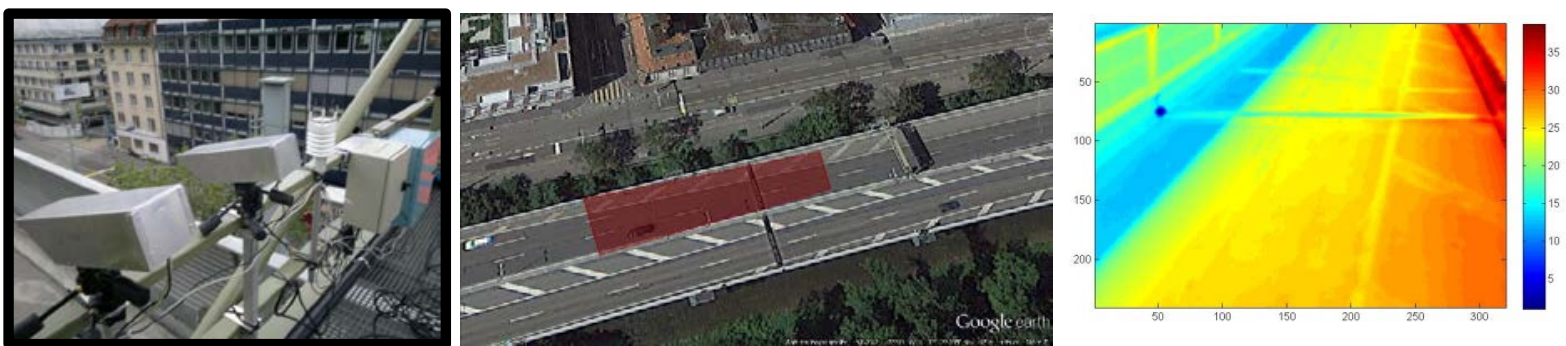

Fig. 2 Experiments carried out on the Sihlhochstrasse bridge in Zurich.

The field of view allowed to survey part of the upper surface of the bridge deck. During our experiments, the sun's course was perpendicular to the main direction of the bridge, which induced a transverse thermal gradient at the deck level for a period during thermal loading (in the morning) and thermal relaxation (at the end of the afternoon and evening). An example of thermal map acquired under traffic is also presented in figure 2.

Second illustration of results presents the measurement system implemented on the shoulder of the "Musmeci" bridge in Potenza, Italy (see figure 3). The infrared camera was mounted on top of the mast at $6 \mathrm{~m}$ elevation from the surface of the bridge deck. The weather station was mounted on the same mast at $1 \mathrm{~m}$ under the camera. A GPS antenna was also fixed at the basis of the mast and at a same elevation than the bridge deck surface. The system was left in standalone acquisition mode during 3 days.

Figure 3 presents an illustration of thermal image acquired in average mode and an instantaneous one showing traffic on the bridge.
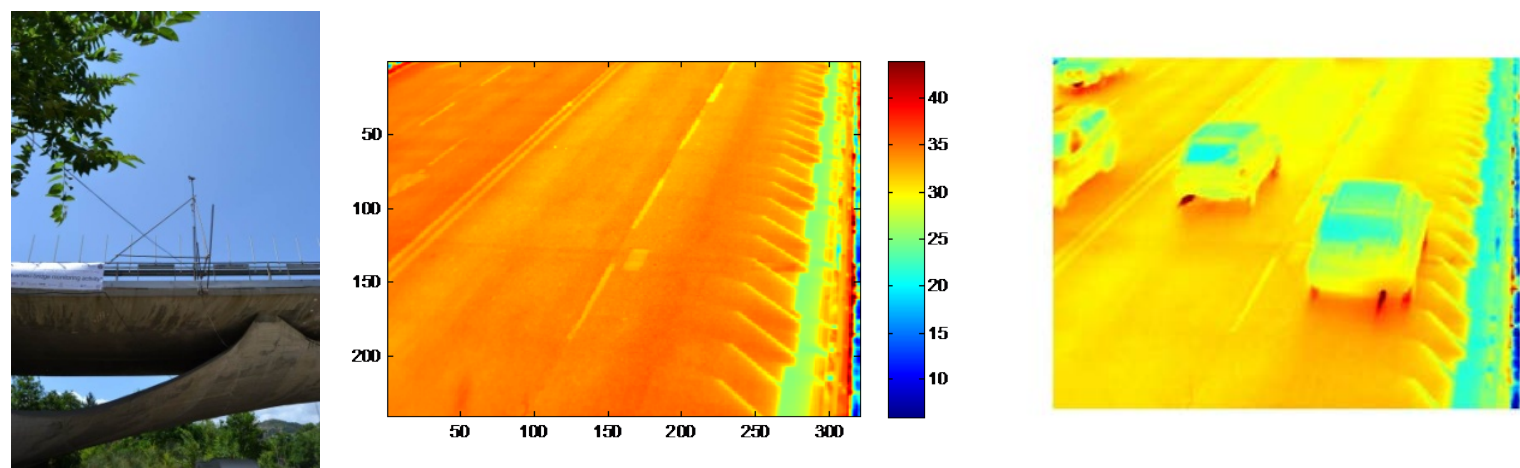

Fig. 3 Experiments carried out on the "Musmeci” bridge in Potenza. 
Figure 4 (left graph) shows the external temperature and the wind speed evolution during experiments. It can be observed on the third day a non-negligible increasing of the wind speed (up to $100 \mathrm{~km} / \mathrm{h}$ ) with in parallel a quasi-constant external temperature.

Figure 4 (right graph) shows an example of results for apparent temperature evolution measured by infrared thermography during experiments.
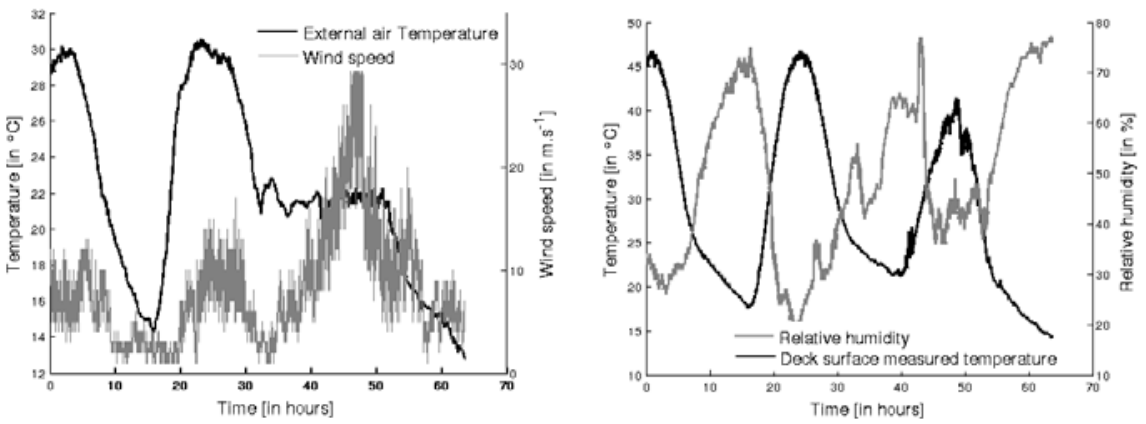

Fig. 4 Measured atmospheric temperature during round 60 hours and wind speed during the same period (left) Measured apparent temperature evolution by infrared thermography and relative humidity during the same period (right).

The thermogram was extracted from thermal image sequence acquired on site. The measured relative humidity shows an abrupt change for relative humidity in particular during the third day. It matches the sudden wind variation but also random direct sun illumination masking by clouds and external temperature stabilization. Combination of convective effect and external temperature reduce the thermal relaxation during night time on the beginning of the third day.

Investigation on inner deck structure was also done by using Singular Value Decomposition. PCT analysis was performed on the complete thermal images sequence but also after extraction of a night period in the full sequence (close to linear thermal relaxation). Figure 5 shows EOF map obtained.
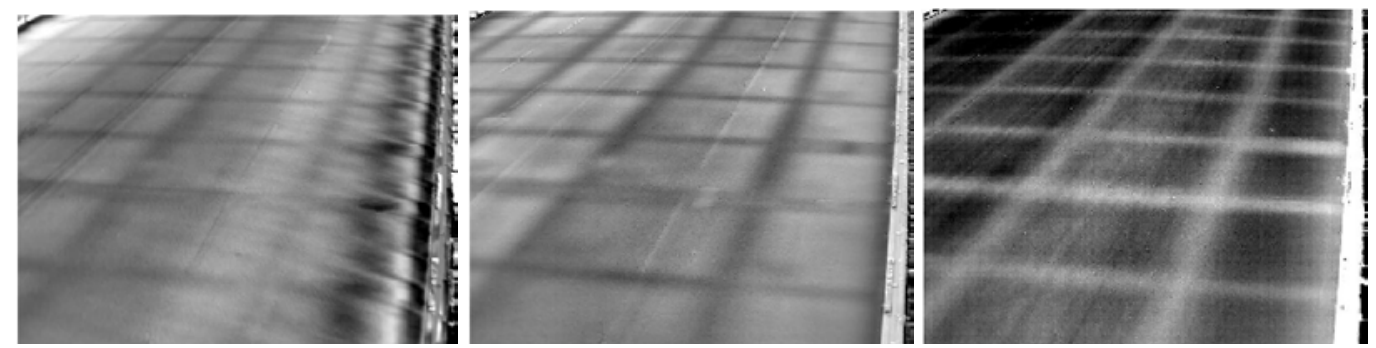

Fig. 5 Full sequence EOF map (left) - Reduced sequence second EOF map (middle) and third EOF map (right).

For full sequence the weight of information concerning the inner structure requires to look farther in EOF maps. For reduced sequence, EOF 2 map give refine sketch of information obtained by full sequence analysis. Finally, EOF map, though it is affected by traffic signature, deliver accurate information on the inner structure of the bridge deck (inner box mapping).

\subsection{Thermal monitoring of reinforced concrete beam over several month}

The SensorBox system presented below is used to monitor structural elements of scale 1 . These elements consist in two reinforced concrete beams ( $16 \mathrm{~m}$ long $\times 1 \mathrm{~m}$ height $\times 0.5 \mathrm{~m}$ width and 21 tons weight). One of these two twin beams has been instrumented with 48 thermocouples and 10 displacement gauges. The second one was damaged by high energetic mechanical impacts carried out at the IFSTTAR falling rocks test station located in the French Alpes [8]. The impacted area (see figure 6) presents, in the rear face of the beam, a leaving of materials that allow to see the rebars. Analysis of the rebar positioning after each impact was presented in [9]. 
The monitoring system set-up is composed of the SensorBox, the weather station, a GPS unit, the infrared camera and a Wi-Fi access point (see figure 6).

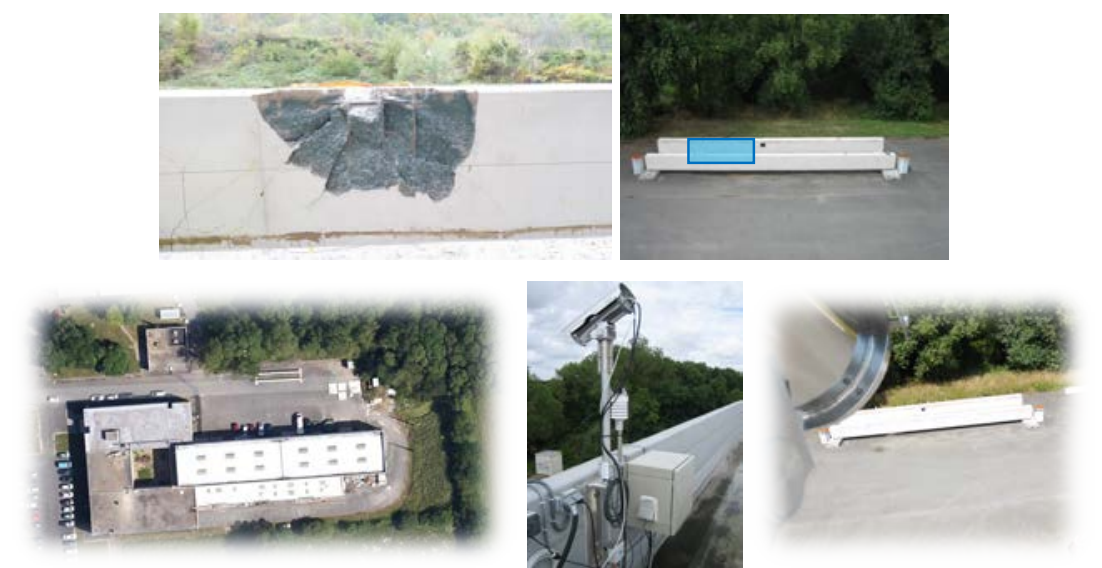

Fig. 6 Long term experiment set-up to monitor 2 reinforced concrete beams in Nantes.

Nine months of data sampled at $0.1 \mathrm{~Hz}$ have been acquired with our designed system. One month break has been done in September for various maintenance operations and technical enhancement of the whole robustness of the system.

During those months, thermal images, air temperature, wind speed and direction, pressure, relative humidity, and rain variations with time have been measured.

Illustrations of thermal images acquired, with these two fields of view, at the beginning of the daily thermal relaxation phase and at its end, are shown in figure 7. The infrared images also illustrate the gain in spatial resolution obtained by changing the infrared camera optic.

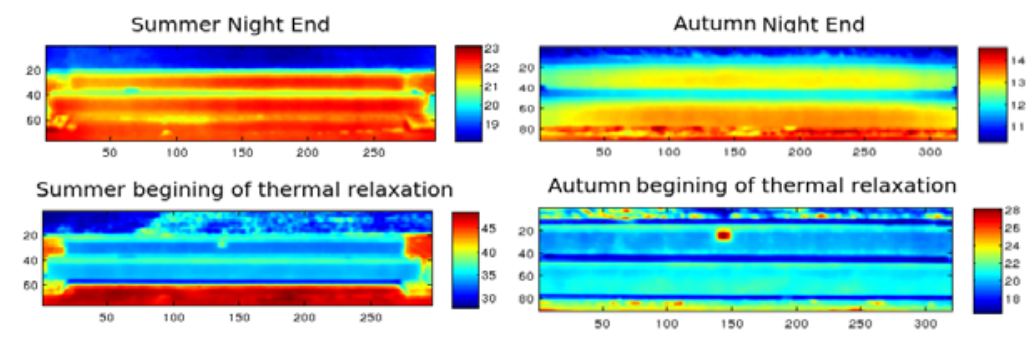

Fig. 7 Examples of thermal images of the 2 reinforced concrete beams in summer and autumn.

In first approach FFT analysis was applied to thermal images sequence. Figure 8 shows results obtained on a thermal image sequence extracted over 10 days in the summer period matching the poorest spatial resolution for FLIR SC325 IR camera configuration.

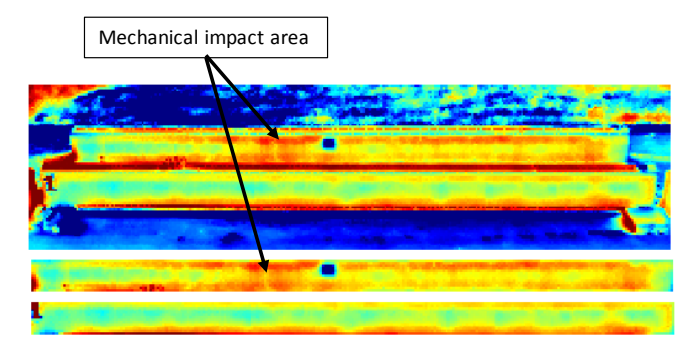

Fig. 8 Phase map of the Full IR scene focused on beam (top) - Phase map zoom on the damage beam (middle) Phase map zoom on the healthy beam (bottom).

\section{Conclusion}

An infrared system has been developed to monitor transport infrastructures in a standalone configuration. It is based on a low cost infrared thermal cameras linked with a calculation unit in order 
to produce corrected thermal map of the surveyed structure at selected time step. With in-line version, data collected feed simplified radiative models implemented in a GPU. With off-line version, the thermal map can be corrected when data are collected under different atmospheric conditions.

This first architecture showed the feasibility and the reliability of a long term use of low cost infrared camera coupled with a mainstream IT system. Further improvement are required on the IT system and its architecture in order to apply autonomously physical model and quantitative estimation procedure on the measured data.

This new software architecture will generalize the notion of Generic programming to allow the full system to process, either, a physical model, a backup or a database feeding without human help. Moreover, and like it has already been done for battery management in the very long term experiment on concrete beams, this way to think will be applied to the hardware architecture in order to couple the whole system with cloud data storage and a GPGPU server allowing the application of enhanced physicals models.

\section{References}

[1] Obran Z, Gutermann. Assessment of masonry arch railway bridges using non-destructive in-situ testing methods, Engineering Structures 31 pp 2287-2298, 2009. doi:10.1016/j.engstruct.2009.04.008.

[2] Rhazi N, Naar S. Aptitude de la thermographie infrarouge à détecter les fissures et nids d'abielle dans le béton 12e Colloque sur la progression de la recherche québécoise sur les ouvrages d'art 2005.

[3] Dumoulin J., Feuillet V., Marchetti M., Sauvagnat T., Ibos L. et Mazioud A. Evaluation de méthodes de détection de défauts, par thermographie infrarouge active, dans des échantillons d'enrobés bitumineux. SFT 2009 Vannes France.

[4] Clarck M R, et al. Application of infrared thermography to the non-destructive testing of concrete and masonry bridges. NDT\&E International Vol 36 pp 265-275, 2003. PII: S0963-8695(02)00060-9.

[5] Grinzato E et al. Quantitative infrared thermography in buildings. Energy and Buildings Vol 29 pp 1-9 1998.

[6] Proto $M$. et al. Transport infrastructure surveillance and monitoring by electromagnetic sensing: the ISTIMES project. Sensors, 10,10620-10639, 2010, doi: 10.3390/s101210620.

[7] Dumoulin J., Averty R. Development of an infrared system coupled with a weather station for real time atmospheric corrections using GPU computing: Application to bridge monitoring, in Proc of $11^{\text {th }}$ International Conference on Quantitative InfraRed Thermography, Naples Italy, 2012.

[8] Jean Dumoulin, Marion Bost, Erick Merliot, Laurent Dubois, Frédéric Rocher-Lacoste, Louis-Marie Cottineau and Frédéric Bourquin, "Design, conception and realisation of high energetic mechanical impacts on a civil engineering structure to evaluate sensing techniques in ISTIMES project framework", EGU2011, Vienna, 03 -08 April 2011.

[9] Catapano I. et al Structural monitoring via microwave tomography-enhanced GPR: the Montagnole test site. Journal of Geophysics and Engineering, Volume 9, Number 4, August 2012, pp 100-107, IOP Science, doi:10.1088/1742-2132/9/4/S100.

Keywords: Infrared thermography, natural environmental conditions, large scale structures, thermal monitoring, outdoor mesurements

Address all correspondence to:

Jean Dumoulin, IFSTTAR, Dpt COSYS, Route de Bouaye - CS4, 44344 Bouguenais Cedex, France

Tel: +33 240845624; Fax: +33 240845998; E-mail: jean.dumoulin@ifsttar.fr or jean.dumoulin@inria.fr

\section{Short Bio}

Jean Dumoulin holds a PhD in energetic systems from the National Institute of Applied Sciences (INSA) in Toulouse. Following positions as associate research engineer in the former Department of Studies and Research in Mechanics and Energetic Systems (DERMES) at ONERA-CERT and associate lecturer at INSA Toulouse, he joined IFSTTAR in 1997 and I4S INRIA team in 2013 . His research interests include infrared thermography, heat transfer, and monitoring using imaging techniques. 